\title{
Discussão sobre a CULTURA e A POLÍtica ECONÔMICA DOS ESTADOS UNIDOS EM Condenada, de Chuck Palahniuk
}

\author{
Thiago Martins Prado \\ minotico@yahoo.com.br
}

\section{INTRODUÇÃO: AS ENTRADAS PARA O INFERNO}

Recorrentes nas obras de Chuck Palahniuk, o estilo sarcástico e a crítica ao consumismo na sociedade contemporânea consagraram, definitivamente, o autor com o romance Clube da luta, em 1996, o qual, posteriormente, foi adaptado para o cinema pelo diretor David Fincher. Com Condenada, Palahniuk inicia a primeira parte de uma trilogia que apresenta uma protagonista de 13 anos de idade chamada Madison, recémchegada ao inferno e filha de bilionários democratas cheios de chavões do "politicamente correto". O artigo em questão analisa como essa obra alegórica de Palahniuk discute tanto a cultura de consumo como a política econômica adotadas pelos Estados Unidos, nos últimos tempos.

No romance Condenada, a necessidade de recordação dos pais por Madison deve ser encarada sob diversos ângulos. De um modo, a fala sobre a formação da protagonista no seio familiar, como qualquer outra obra romanceada, fornece pistas para os leitores a fim de compreender as peculiaridades da personagem (enquanto ela busca o seu autoentendimento). De outro modo, pelas impressões de Madison, podem-se enxergar as críticas à família por meio de um processo metonímico: embora Madison ironize os comportamentos do pai e da mãe 
no microcosmo, a intenção é tratá-los como exemplos de uma boa parcela da sociedade estadunidense, que disfarça um modelo exploratório global sob os elogios mais cínicos ao desenvolvimento corporativo atrelado a uma concepção mercadológica de cidadania.

Com maior precisão, no capítulo III do romance Condenada, Chuck Palahniuk descreve o ambiente da protagonista: Madison, a quem o título de condenada se aplica, possui 13 anos, é gorda, sarcástica e tem um vocabulário acima do padrão da idade - o que se associa a seu caráter solitário e agudamente crítico. O que a coloca numa posição privilegiada para a discussão a respeito da cultura consumista estadunidense não se dá meramente pelo acidente de ela ter morrido e poder reanalisar os seus passos na pós-morte, mas sim pelo fato de ela, ao mesmo tempo, ter pertencido a uma linhagem privilegiada economicamente de pais democratas - com um pai empresário bilionário e uma mãe atriz de fama hollywoodiana - e de ela adotar uma postura desajustada ou politicamente incorreta num lar que se define pelo politicamente correto.

Por causa dessa precedência familiar, em vários momentos, a versão do inferno mais relatada pelos pais de Madison adota uma aplicação classificatória de uma moral baseada nos chavões democratas: inferno é o lugar para onde vão as pessoas que usam casacos de pele ou onde estão os que compram condicionador testado em coelhinhos, e Ann Coultar, polemista conservadora republicana, é que seria o diabo em carne e osso. Inclusive, a oposição entre a visão substantiva e adjetiva do inferno, na concepção dos pais de Madison, serve como um dos elementos para organizar a divisão política da sociedade norte-americana: a crença em Deus ou no Diabo e na conduta moral provinda da Divindade pertence mais ao jogo manipulatório dos republicanos e da bancada dos pastores enquanto que, para os democratas mais atualizados, a única razão para forçar determinados comportamentos no ser humano seria a fidelidade ao contrato social. O pecado, por consequência, seria escolher os objetivos a ser percorridos na vida de uma forma inadequada. Desse modo, a não aceitação das formas substantivas do sacrário é um dos motes a constituir a dignidade do pai de Madison em ser um democrata ultramoderno. Entretanto, ao afirmar que "até assassinos em série merecem TV a cabo" (PALAHNIUK, 2013, p. 24), o pai de Madison, ao contrário de estar parecendo reforçar a oposição entre republicanos e democratas, confirma ainda mais a versão hegemonicamente econômica como critério a avaliar 
a justiça entre os estadunidenses, entendendo, nesse caso, a participação no consumo como forma de integração social por excelência.

Em verdade, a descrição dos pais por Madison é um dos recursos que Chuck Palahniuk realiza no romance Condenada para denunciar o fato de que a divisão da sociedade estadunidense em conservadora e liberal é oportunista em diversos temas, como a preservação do meio-ambiente, as políticas de adoção, a imigração, o mercado, o uso de tóxicos, etc. Ela sinaliza para uma dicotomia artificial que simplifica posições como boas ou más e retira a complexidade das opiniões e argumentos; ela serve para injetar e organizar valores nos cidadãos norte-americanos para melhor manobrá-los.

No caso dos pais de Madison, especificamente, nota-se que a política do discurso encobre as ações cotidianamente contraditórias. Por exemplo, ainda que a consciência de preservação socioambiental seja sempre declarada na família da protagonista, tanto o pai quanto a mãe gastam grande quantidade de combustível fóssil em seus jatinhos particulares para tratar de banalidades. A mesma contradição ocorre quando os pais valem-se das adoções de menores de países periféricos motivados por golpes publicitários - uma espécie de caricatura do casal Brad Pitt e Angeline Jolie. Sobre o tema da imigração, a mãe de Madison defende a livre entrada dos latinos para exercer profissões de subalternidade e consumir produtos culturais dos Estados Unidos, sem, com isso, fazer o mínimo esforço para compreender-lhes a cultura.

Outras incoerências entre o discurso político e a efetiva ação na família de Madison estão espalhadas no romance inteiro: tais como a preocupação maior em combinar trajes quando se dá o uso de fitas de cor em casos de protestos simbólicos (volta de soldados, mudança climática) ou ações de estímulo à consciência pública (prevenção ao câncer de mama ou à Aids); ou ainda, a defesa pelo uso recreativo de tóxicos baseado meramente no prazer individual e sem qualquer discussão sobre quaisquer impactos sociais. Nesse item, é pertinente comentar o discurso enfurecido dos pais contra o processo de produção do milho exposto à radiação enquanto se apresentam por demais tolerantes com a periculosidade da mistura dos componentes químicos na maconha por eles fumada.

A crítica maior da personagem principal de Condenada sobre a educação dos seus pais reside no aprendizado da esperança. Para Madison, a sua entrada no inferno na pós-morte acentuou a suspeita a respeito da esperança como uma forma de vício na sociedade contemporânea: uma 
espécie de conservação de uma preguiça em tomadas de decisões que reativa postergações ad aeternum. A esperança inibe a atitude radical capaz de mudar o ambiente ao mesmo tempo em que ilude o indivíduo com uma imagem de autodesenvolvimento a congelar uma perspectiva paradisíaca que, embora esteja distante e inacessível, é vista como um modelo de sucesso ou de conquista a ser perseguido.

No romance Condenada, a pretexto da discussão das reflexões da protagonista Madison sobre a influência dos pais em sua formação, Chuck Palahniuk permite problematizar alguns traços da cultura e da política econômica contemporâneas dos Estados Unidos, como a instrumentalização dos conceitos de liberdade e de esperança, a relação entre demanda de mercado e cultura, além das consequências do fato de a política norte-americana estimular a exponencialização das dívidas do Estado e do cidadão.

\section{DA POLISSEMIA DO INFERNO E DE SEUS HABITANTES}

A frequente recorrência da palavra inferno no livro Condenada, de Chuck Palahniuk, sugere, invariavelmente, um contexto específico de discussão: o valor das imagens consumidas pelo homem na contemporaneidade. Dentro desse plano constante de análise, Palahniuk testa a polissemia do termo inferno denunciando os ajustes das interpretações sobre tal palavra para atender a demanda de valores contemporâneos incitados pelo frenético consumismo.

De imediato, logo na apresentação do capítulo I, Madison, protagonista do livro, observa a sua condição de condenada no inferno como um resultado da ausência de prazer com a sua autoimagem. Por ser uma garota obesa e, portanto, por possuir uma imagem desviante do padrão exigido de consumo, a personagem concebe, inicialmente, o inferno como o espelho negativo e fracassado das expectativas propaladas e gerenciadas como imagens de bem-estar. O inferno é, desse modo, a confirmação punitiva para aqueles que não se realizam nas promessas esperançosas e imagéticas da Terra; e, como tais promessas aninhadas às imagens-padrão de sucesso não se sustentam para a maioria dos homens, a Terra acaba por ser o retrato do inferno. Assim como a própria personagem Madison afirma, "o que faz a Terra se parecer com o Inferno é a expectativa de que se pareça com o Paraíso” (PALAHNIUK, 2013, p.11). Tal afirmação 
da protagonista surge ainda mais confirmada quando ela compara a sua condição de morta no inferno às formas anestesiadas do mundo dos vivos: as maravilhas anunciadas pela televisão e o encantamento da efemeridade permanente da internet movem os olhos, mas paralisam os corpos. Em verdade, Madison considera o aprisionamento no espetáculo como um frequente treino para a morte - o reforço à passividade, paradoxalmente, resulta da vida multicolorida e da pluralidade de possibilidades de aventuras dentro das telas que, como medusas, proclamam um espelho de multiplicidade de vivências para manter um cenário mórbido recheado de expectativas. A contradição maior da vida-morte contemporânea é que, num mundo em que o indivíduo se escraviza na produção para tentar trazer para si a idealidade do consumo, a morte é desprezada como um fracasso. A caricatura feita à morte é confirmada pela anestesia do trabalho cego em direção ao padrão de compra: acredita-se que quem morre está fora da ordem produtiva, sem que se perceba que o próprio imperativo do trabalho é o que anula a vontade de experimentar a vida.

Cabe citar o próprio pensamento dos pais de Madison a respeito da morte: eles não conseguem conceber a morte como um acidente capaz de interromper a razão produtiva. Ao contrário disso, eles enxergamna como um resultado do não se cuidar adequadamente, de não aderir de forma bem ajustada à higiene democrática (moral e política) da oportunidade e do bem-estar derivados do trabalho (PALAHNIUK, 2013, p.106). A morte aqui é vista como um "extremo lógico", implicada pela arritmia ou pelo desconhecimento das leis liberais da economia, que, hipocritamente, impõem modelos de vivência, assassinando a criatividade e as possibilidades de desvencilhar, do controle do capital, a caracterização dos perfis humanos. Essas interpretações a respeito da morte fisiológica, desprezando-a ou ajustando-a sob a hegemonia do capital, preservam a morte simbólica.

É por isso que, no capítulo IV, ao colocar em equivalência a morte dos condenados no inferno com a dos personagens dos desenhos animados da Warner Bros, que são restaurados por completo, depois de mortos, para os próximos assaltos, Madison está denunciando a contínua destruição de indivíduos na cena contemporânea, em paralelo com a perpetuação dos tipos na ordem produtiva, sistema que gera, ao mesmo tempo, conforto e monotonia.

A história do inferno e do diabo retoma, por semelhança, a história do sacrifício dos homens: o relativismo cultural descrito no capítulo V, 
que aponta a transformação contínua de um deus em força maligna por uma civilização vencedora em relação à primeira, não só aponta para a nulidade das instituições sagradas (esvaziadas da verdade e inspiradas pelo poder manipulatório) como também indica o absurdo do homem em ter, muitas vezes, desperdiçado sua existência ao dedicar-se à crença na esfera do sagrado.

$\mathrm{Na}$ perspectiva inicial da personagem Madison, um sentimento generalizável encobre o absurdo do viver baseado na produção (ou com necessidade de crenças religiosas) que engana a todos graças a um ritmo que mantém programada a vida. Trata-se da esperança. A esperança é entendida simultaneamente como um erro e um castigo, um vício e uma fraqueza. Segundo a protagonista, a atmosfera da pós-morte do inferno propicia a cura do mal da esperança. Com outro teste de interpretação bem peculiar sobre o inferno, Madison enxerga, no ícone de Satã, a personificação do esgotamento das esperanças, ou seja, a imagem imediata do antídoto contra a aceleração anestesiada do ritmo de produção e consumo - é nesse sentido que deve ser entendida, excetuando-se a penúltima e a última partes do livro, a insistência da protagonista por chamar a atenção do Diabo em todas as aberturas dos capítulos. A própria Madison atribui para si, ainda que tenha chegado ao inferno, o mal da esperança, classificando-se como uma vítima da Síndrome de Poliana - uma perseguidora do pote de ouro no inexistente final do arco-íris (PALAHNIUK, 2013, p.135). Não é de se admirar, sendo uma personagem protagonista que identifica sua própria doença, mas não se consegue tratar (como Madison aprecia em Goran, seu irmão adotado), a ausência de ambição, uma espécie de desajuste que o protege da praga da esperança (PALAHNIUK, 2013, p. 143).

Entretanto, no decorrer da narrativa, a capacidade de Satã ser um símbolo purificador do mal da esperança vai se tornando cada vez mais questionável. Num primeiro momento, no capítulo VI, em seu tom autocrítico, Madison satiriza a própria necessidade de buscar um consolo de uma autoridade parental adulta disponível no mundo infernal depois que pais, professores e nutricionistas perderam a validade. Isto é, Madison reconhece a continuidade de uma relação hierárquica de mando, que gera dependência, conforto e expectativa de autoaperfeiçoamento concomitantemente. Nos capítulos finais do romance, essa acidental e sarcástica antecipação é confirmada quando Satã afirma ter escrito todo o roteiro da vida de Madison. Ao invés de o inferno ser o espaço de 
rebeldia por eras de manutenção adiada, como vizinhança marginal que se deteriorou ao extremo, como se sugere no capítulo XXXII, ele é mais uma dimensão estereotipada de condenação e de periferia necessárias para permitir que a balança do condicionamento e da manipulação sociais permaneça equilibrada. Nesse caso, a condenação do homem não se faz pelo seu livre-arbítrio, mas pela ausência de liberdade - isto é importante de ser dito, pois se trata de uma inversão dos valores da tradição judaicocristã, que determina a culpa advinda da escolha. Nessa tradição, tanto a imagem diabólica do Mal Maior como a do homem na origem dos tempos carregam uma correspondência entre o ato livre (aos olhos de Deus indevido) e a cena de expulsão da esfera celestial (Lúcifer) ou do paraíso (Adão e Eva). Preservando a condenação (mas retirando o poder de escolha dos homens), precisamente, no antepenúltimo capítulo do romance de Palahniuk, ocorre a revelação de Madison de que Satã, muito ao contrário de fortalecer o ato de desobediência opositora e libertária da norma moral, reforça a lógica de condicionamentos entre os homens. Tal epifania é combinada à fala sobre a falsa liberdade que o Diabo nos propõe, pela qual a sociedade contemporânea deixa-se iludir. No romance Condenada, três passagens que se valem do recurso da analogia (a tecla Control do computador) podem ser evocadas para justificar a farsa da liberdade estimulada tanto pela imagem do inferno como pela do mundo atual. No capítulo I, a mãe de Madison controla os movimentos de uma empregada somaliana trancando quartos por meio de comandos no computador a três continentes de distância (Control $+\mathrm{L}$ ); no capítulo XX, o demônio Akibel vale-se do computador para checar o histórico da personagem Goran (Control + Alt + F); no capítulo XXXVI, Madison resume a gestão da sua vida à comparação dos controles computacionais às mãos de Satã (Control + Alt + Madison).

Dentro desse contexto, conforme Zygmunt Bauman (2001, p.30), a contemporaneidade estabeleceu um singular conceito de liberdade estando entregue à competência individual. Nessa perspectiva, é importante observar que as agendas utópicas de libertação política da modernidade foram substituídas pela presunção de liberdade de escolha, e as instituições sociais estimularam a apreensão individual sobre a diversidade do vestuário das identidades. Por mais que o indivíduo possa parecer o centro de sua liberdade dentro dessa dimensão, paradoxalmente, é impossível não pensar essa concepção atrelada ao mecanismo de 
ajustamento social - um disfarce em que liberdade e libertação tornaramse antípodas.

Mas por que foi interessante incitar um modo de pensar a liberdade num plano de contingência individual? Por que Madison tem que se deixar iludir por seu pseudodomínio sobre a própria individualidade e apostar, com estultícia, na personificação do mal como atestado extremo da sua liberdade contra quaisquer modelos de moral? Uma parte da resposta é dada pelo próprio sociólogo polonês: segundo Bauman (2001, p. 98), o incentivo à realização das fantasias pessoais e à remontagem contínua dos disfarces identitários, que compõe a base da liberdade individual contemporânea, sustenta-se na estratégia da diversificação do consumo. Poder ser diferente e comprar identidades no mercado das personalidades e das ideias prontas e armazenáveis constrói a possibilidade do compartilhamento, do uso e da valorização da liberdade individual.

Considerando a radicalidade das concepções e das referências encontradas no romance Condenada, outra parte dessa resposta pode ser encontrada no fato de a lógica bancária depender de uma crescente economia de mercado multidirecional, variável e repleta de estímulos identitários (oposicionistas ou não) a fim de que a elevação contínua de mais consumidores - aqui entendida como espaço de liberdade individual - não cesse ou interrompa a cachoeira de crédito necessário para realimentar a emissão de moeda e de títulos do tesouro. Nesse sistema de consumo, as pessoas precisam ser consideradas veículos para a produção de mais capital em que o desejo humano reduz-se ao sinônimo da sua demanda como comprador. Na visão de um dos documentaristas de economia mais polêmicos do sistema bancário estadunidense, Peter Joseph, em seus filmes Zeitgeist: the movie, Zeitgeist: addendum e Zeitgeist: moving forward, o mecanismo do agigantamento do exército de consumidores é derivado da fundamental geração de débitos e juros que, invariavelmente, retroalimenta a criação de mais moeda para pagálos e disfarça o crescimento da economia. Acontece que, sendo o Federal Reserve uma corporação internacional privada com fins lucrativos e com monopólio sobre a emissão do dólar desde 1913, tal emissão é feita mediante empréstimo ao governo dos Estados Unidos por meio de promessas de pagamento chancelados pela troca em títulos do tesouro nacional e com juros embutidos. Antes de Joseph, o colunista de economia política William T. Still, em seu estudo The money masters, de 1996, afirma que, por meio desse processo, os políticos precisam subir 
os impostos de produtos e serviços e estimulá-los constantemente para pagar esses juros; só que, paradoxalmente, a aceleração desenfreada da produção e do consumo implica uma circulação monetária maior e, consequentemente, mais emissão de moeda e mais juros - o que faz com que o governo capte tais recursos através do custo inflacionário pago pela população trabalhadora e consumidora. O problema é que isso se torna um círculo vicioso: quanto mais dinheiro em circulação menos ele vale, e quanto menos ele vale, mais há a necessidade dele - e, portanto, mais juros - para suprir as eventualidades do mercado.

O romance Condenada, nesse ponto, explica que ao cidadão dos EUA a liberdade (entendida sempre no plano individual) somente pode ser imaginada pelo seu poder de consumo. Quanto mais consumo, mais liberdade - essa mesma lógica, todavia, encarcera o indivíduo e o Estado em seu endividamento de proporções geométricas. De uma forma ainda mais impiedosa, em Condenada, o inferno ou o Diabo não confrontam tal lógica como uma dimensão alternativa a esse projeto. A dicotomia bemmal, tal como a dualidade democratas-republicanos, auxilia a construção de uma falsa liberdade que direciona as escolhas dos indivíduos, ainda que esses não notem, ao aprisionamento das suas forças produtivas.

\section{DOS CASTIGOS DA DÍVIDA}

As consequências desse processo de endividamento monetário do Estado e do cidadão aparecem de três modos que podem servir para explicar as posturas de Palaniuhk em seu romance Condenada: a) a aposta na diversificação das identidades para aquecer o mercado; b) o controle do valor das mercadorias e serviços por meio da política econômica de alimentação seguida de retração de crédito; c) o estímulo ao desperdício de produtos e à irrelevância de serviços.

Quanto ao primeiro item, pode-se afirmar que a polêmica de esse escrito de Chuck Palahniuk satirizar diversas minorias, como os homossexuais, os idosos, os imigrantes, os judeus, os afrodescendentes, as feministas, deve-se ao fato de enquadrá-las tão somente à fala de Madison eivada de críticas ao cinismo da política econômica dos Estados Unidos e, principalmente, dos seus pais democratas. Como um dos exemplos mais significativos e caricaturais do livro, no capítulo XV, há uma descrição oportuna de uma das defesas da mãe da protagonista ao tratar do tema 
da imigração. Para ela, as mulheres de alguma teocracia radical estariam bem empregadas como massagistas ou manicures nos bastidores de uma produção hollywoodiana de filmes elevando o nível das narrativas cinematográficas e tornando-se predadoras sexuais ao comprar unhas de acrílico. Assim também como o ápice da democratização cultural estaria no poder de compra das minorias em relação aos próprios filmes. Na perspectiva de Madison, fica claro como a política de integração socioeconômica é baseada num padrão de sucesso que serve à imposição de um modelo de ganhos e de gastos de capital e como o discurso do neoliberalismo econômico empreende uma cultura da exploração como se fosse libertação.

É nesse ponto que o entendimento sobre o poder simbólico do consumo de Palahniuk aproxima-se mais das ideias do historiador Russel Jacoby que das alegações realizadas pelo semiólogo Jesús Martín-Barbero. Para Barbero (2006, p.292), pelo fato de o consumo não somente ser uma reprodução de forças, mas também um espaço de produção de sentidos, é necessário que esse fenômeno social de gasto de capital não seja meramente compreendido pela posse dos objetos, já que os usos na cena do consumo geram formas sociais que manifestam demandas e estratégias advindas de uma série de dimensões culturais. Contrariamente, Jacoby (2001, pp.72-73) afirma que a especialização dos segmentos culturais no consumo não estabelece identidades capazes de enfrentamento com as forças homogeneizadoras da sociedade industrial avançada. Embora, às vezes, possa ocorrer um detalhamento maior de um produto ou de um serviço para atender as características de um nicho cultural específico no mercado, o historiador Russel Jacoby não reconhece aí um espaço de luta para a afirmação de uma identidade, e sim um processo de fetichização da diferença que, ao agregar valor à mercadoria ou ao serviço, alinha-os aos padrões de atividades e de desejos já substancialmente propagados pelos modelos de ganho e de gasto de capital - a integração das diferenças pela cena do consumo permite fantasiá-las na norma.

Interessante notar como a crítica de Palahniuk às estratégias e às referências da política de identidade cultural estadunidense vai evoluindo ainda mais a partir do capítulo XXVII. Assumindo as influências do pensamento de Foucault (2006, pp.74-76) a respeito da dinâmica do poder, os principais teóricos dos estudos culturais, tal como Stuart Hall e Jesús Martín-Barbero, tenderam a declarar que os focos de disputas de representatividade socioculturais são particulares (não centrados 
em vontades universalizadas), pontuais (variáveis de acordo com as circunstâncias) e negociáveis (móveis dentro das articulações de poder); portanto, foi no campo da indefinição e da flexibilidade que os estudos culturais reconheceram sua possibilidade de encenar um terreno político para falar de identidades. Tal estratégia culturalista parece agigantar-se no capítulo XXVII de Condenada, quando Madison afirma que é a identidade fixa que serve de instrumento de tortura para as representações humanas no inferno, e mais ainda se torna preponderante no capítulo XXX, quando a protagonista utiliza o recurso da mobilidade identitária como oportunidade de enfrentamento do demônio Baal no inferno, que apenas pensa a lógica do poder pelo viés unilateral e preserva a estereotipia como comando. No capítulo XXXI, ao continuar com essa mesma tática política, Madison derrota lideranças históricas no inferno e ascende como nova líder, conquistando multidões; entretanto, como consequência, ela realiza uma política de integração tornando essas representações sociais bem-ajustadas e produtivas dentro de um projeto de geração de empregos que serve para ocupá-las eras a fio, exclusivamente. Ainda nesse mesmo capítulo ocorre outra revelação para Madison: o seu teste de culpabilidade resulta-lhe em inocência, ou seja, ela não deveria estar no inferno, e sim no céu. A partir disso, nota-se a sátira corrosiva de Palahniuk que tanto serviria para as tradicionais como para as novas lideranças políticas: aqueles que deveriam estar no céu são os que mais levam os outros ao inferno - Madison, no caso, é uma das que mais contribuíram com a lotação do inferno na função de operadora de telemarketing e a que mais conseguiu entorpecer as massas com o seu perfil de liderança. A visão de Chuck Palahniuk é de que isto que se chama de novas lideranças a partir das políticas multiculturalistas, em verdade, preserva a lógica exploratória do capital financeiro internacional, pois atende à demanda de mais posicionamento de postos de trabalho e de mais consumidores para manter o aquecimento do mercado e, dessa forma, a economia real (baseada em produção e serviços) poder sustentar o parasitismo da economia virtual (baseada em empréstimos e cobranças). Como Russel Jacoby (2001, p.62) denuncia, o maior problema das políticas multiculturalistas são as suas contínuas declarações de mudanças em meio ao predomínio da uniformidade da política econômica.

Quanto ao segundo item, o controle do valor das mercadorias e serviços por meio da estratégia econômica de alimentação seguida de retração de crédito, pode-se afirmar que, segundo William T. Still 
(1996), a facilitação de empréstimos, ao invés de fornecer capacidade de redistribuição ou de crescimento de renda, reforça o controle do capital e da ordem produtiva pelas corporações bancárias. Isso porque, seguindo as orientações da Mecânica Monetária Moderna definida pelo Fed, os bancos estadunidenses emprestam um valor de, aproximadamente, 90\% acima dos depósitos garantidos em conta - o que, inevitavelmente, faz com que o nível de empréstimos seja extremamente superior ao de depósitos e, por consequência, as dívidas preponderem acima do capital circulante. Sendo assim, nos ciclos de oportunas reduções de concessão de crédito, a inevitável atmosfera de inadimplência, de falência e de risco de desemprego pode fazer com que as posses daqueles que se endividaram caiam a preços irrisórios e possam ser arrematadas pelos próprios credores, as instituições bancárias, a valores que, diversas vezes, ainda preservam o resíduo da dívida e o retorno dos juros, tornando escravo tal pagador. Essa escravidão contemporânea é descrita por Peter Joseph (2011), ainda dentro desse próprio mecanismo de estímulo e retração cíclicos de crédito bancário, quando afirma que um trabalhador endividado tem chances maiores de se submeter a baixos salários e ao enfraquecimento dos seus direitos frente à empresa contratante, que o visualiza como uma mercadoria de valor barato - determinado, em parte, pelo risco do não pagamento das dívidas.

Logo no capítulo inicial de Condenada, Chuck Palahniuk ilustra algumas passagens que mostram como a escravidão contemporânea tornou-se um processo global. Num desses momentos, a mãe de Madison, por meio de um programa de computador que a preserva em outro continente, diverte-se com sadismo ao trancar uma empregada somaliana num dos quartos de uma mansão na capital parisiense, uma das moradias inabitadas dos pais da protagonista espalhadas ao redor do mundo. Nessa perspectiva, observa-se como a diferença de renda contribui para o cerceamento e controle dos espaços sociais por parte dos mais abastados em relação aos mais necessitados: por onde os desfavorecidos devem passar ou a imobilidade das cenas sociais são resultado da sensação de posse de umas pessoas em relação a outras - justificada pelo simbolismo do capital - ao mesmo tempo em que a distância fornece segurança suficiente para que pareça simulação a brincadeira com ratos-humanos de laboratório, embora isso ocorra por meio de efeitos extremamente nocivos e reais para quem os sofre. 
Em relação à proteção que tal distância fornece, Palahniuk, ao contrário de defender o discurso-padrão de democratização do saber e de dar oportunidade ao livre desenvolvimento pessoal, evidencia que o avanço dos softwares e da internet possibilita sofisticadas ferramentas de manipulação social que geram eficiência para, simultaneamente, neutralizar a materialidade do embate e para alargar a geografia do controle. Potencializar os rumos dos empréstimos, expandir os cenários de consumo, multiplicar os trades entre diversas corporações e países ou acelerar a emissão e a virtualidade da moeda, tudo isso foi facilitado pelas tecnologias de rede e pode ser traduzido por meio da seguinte frase de Palahniuk (2013, p.7): "afetar o ambiente sem estar fisicamente presente". A partir de uma tela de computador, uma simples operação no teclado pode endividar uma quantidade gigantesca de pessoas e acarretar para elas uma elevação no ritmo de trabalho estimulada pelo custo inflacionário ou pelo sistema de juros embutidos na dívida - elas tornam-se escravas de um patrão invisível, às vezes um software que replica procedimentos e informações continuamente.

No mesmo capítulo inicial, ainda dentro da lógica do "afetar o ambiente sem estar fisicamente presente”, Chuck Palahniuk coloca como análoga a situação da posse de uma música de sucesso gravada há décadas ocupando a mente de um trabalhador em regime semiescravo na China, numa realidade a qual o autor da música nunca conhecerá. Essa articulação direta entre a expansão do mercado global de consumo e o modo de produção chinês denuncia, de imediato, como propostas tão distintas de políticas, uma capitalista e democrática (EUA) e outra comunista e autoritária (China), aliam-se, em intrínseca cumplicidade, para pactuar, equilibrar ou disputar (dentro do mesmo jogo) os interesses corporativos e as áreas de livre comércio. Por mais que se tenda a associar os grandes superavits comerciais e o acúmulo de uma enorme reserva de moeda estrangeira a uma política econômica mercantilista da época de Thomas Mun (FORTINO, 2013, p.35), o que se pode afirmar é que o modo de produção chinês, antes de representar uma revitalização do regime comunista, em verdade, fortaleceu e agigantou as possibilidades do contemporâneo capitalismo corporativo e financeiro. Ao lado da continuidade da política monetária de garantias de ritmo na emissão do dólar sustentada pelo Federal Reserve, as decisões do governo chinês colocam-no como um dos parceiros econômicos que mais compram títulos do Tesouro nacional estadunidense e, portanto, um dos que mais 
geram credibilidade e lubrificação às estratégias monetárias aplicadas pela gestão financeira do governo dos EUA, do Fed e dos conglomerados bancários internacionais. Ao lado das multinacionais de larga expansão mundial, a farta e barata mão de obra chinesa (facilmente renovável e com escassos direitos trabalhistas) oferece imensas vantagens para a redução nos custos de produção.

Do mesmo modo, para essa massa de trabalhadores, os produtos culturais ocidentais que já tenham sido depreciados por sua intensa circulação e que não comprometam as ideias do regime chinês podem ser refugados como material instigador do uso de internet (com seus recursos de estímulos a propagandas e de administração de resultados de pesquisa). De acordo com a ilustração palahniukiana, uma música de sucesso, depois de décadas, pode ainda habitar o cérebro de um operário chinês com uma exaustiva carga de trabalho. Interessante associar esse fenômeno ao fato de, em 2009, os usuários da internet da China ultrapassarem toda a população dos EUA preservando um hábito em larga escala não questionado pelo governo chinês: downloads de músicas pirateadas. Em O jeito Google de trabalhar, de Ted Remerowisk (2010), fica nítida a cumplicidade que a ferramenta de busca mais consagrada no mundo global possuiu em relação à censura do regime chinês até o ano de 2010: 0 Google, para funcionar com escritórios na China, concordou em bloquear resultados de pesquisa que pudessem comprometer o controle político do comunismo chinês. ${ }^{1}$ No início das relações com a rede de computadores, a tolerância do governo chinês com o hábito de seus cidadãos de baixarem músicas pirateadas, tanto em casa como em cybercafés, aponta para uma possibilidade de descarga de pequenas contravenções no ambiente privado que, por serem catárticas, inibem qualquer contravenção programática e coletiva contra o regime político. Nesse caso, aquele artista que se orgulha de ter passado pela censura chinesa com a sua obra, ao contrário de um libertador, deve ser entendido como mais um cúmplice da escravidão contemporânea em limites chineses. Garantindo a política

1 Tal acordo foi abalado quando o Google sofreu um ataque em seu sistema de dados em que foram invadidas contas de ativistas políticos e defensores de direitos humanos, tendo por suspeita maior para a invasão membros do regime comunista chinês (REMEROWISK, 2010). É preciso compreender certo abalo não como fruto de uma ética política ou respeito aos princípios democráticos. A razão maior estaria no risco da perda de credibilidade quanto aos sistemas de segurança no buscador poder levar a perdas financeiras consideráveis para a corporação. 
monetária de emissão do dólar, fornecendo mão de obra volumosa e de baixo custo às multinacionais e contribuindo com a criação de uma massa de consumidores de um mercado específico de produtos culturais ocidentais já depreciados pelo tempo, o comunismo de mercado chinês, paradoxalmente, é o celeiro do capitalismo corporativo e financeiro.

Outracontradiçãoqueserelacionaà ordem econômica contemporânea é que, quanto mais a política de emissão monetária do dólar é vigorosa, mais a materialidade da moeda é negada. De início, desde 1971, o lastro de correspondência entre o dólar e o ouro foi abandonado, tornando o valor de tal moeda virtualmente fixado pelo Tesouro dos EUA (FORTINO, 2013, p.25). Sem conversão em ouro, o dólar virou o fundamento de uma crença em valores tão irreais quanto qualquer divindade, contudo com maior poder dogmático que qualquer deus. No capítulo XIV de Condenada, o fato de Palahniuk afirmar que doces, marshmallows, amendoins, cerveja preta, pipoca e outras dessas especiarias eram a moeda no inferno soa cômico porque parece estar longe do dólar reverenciado pela economia mundial contemporânea. Entretanto, a sátira palahniukiana reside exatamente em declarar o valor do dinheiro baseado na fé. É nesse momento que a situação de referência de valor tanto em doces quanto em dólares pode ser ridicularizada igualmente.

De outros modos, também a virtualidade do dólar cresce à medida que sua política monetária consolida-se. Segundo Peter Joseph (2007), para o âmbito da economia estadunidense, apenas cerca de 3\% do dólar corresponde ao papel-moeda emitido. Conforme Hakim Bey (2012, p.112), mais de 90\% desse padrão monetário não se prende à esfera da produção. Eles ocorrem como informações de transações baseadas em cálculos de juros e negociação de débitos, empréstimos ou ainda como estímulo ao risco excessivo, dos gigantescos derivativos - que, de 1970 a 2008, tiveram um crescimento em média de $24 \%$ ao ano, chegando a 20 vezes o produto interno bruto internacional (FORTINO, 2013, p. 265). Bey (2012, p.40) reconhece, nesse fenômeno, fertilidade contranatural e alquimia de expropriação que declaram mais a ausência que a presença, mais o débito que a riqueza.

O sistema de reserva bancária fracionada e a acumulação de juros compostos aumentam a necessidade da moeda por meio da dívida e é na dívida que a moeda (criada do nada) demonstra seu maior poder. Quanto mais o endividamento cresce, mais há a urgência de capital circulante para o sustento da própria elevação da dívida, e o dinheiro jorrado no mercado 
nessa circunstância aparece com certa depreciação por causa do custo inflacionado de mais emissão. Se esse mecanismo de dívida estimulando geração de moeda tende a se exponencializar como uma projeção infinita, então serviços e produtos devem ser ajustados a essa perspectiva. Nesse sentido é que se deve comentar a terceira consequência do endividamento monetário do Estado e do cidadão: o estímulo ao desperdício e à irrelevância dos serviços.

Como ilustrações pertinentes, em Condenada, no capítulo XIII, a mãe de Madison, ao ser escolhida para a leitura do vencedor do Oscar de melhor filme, compra um bilhão de envelopes dourados com cartões brancos apenas para treinar o momento de entrega da estatueta. Nesse mesmo capítulo, Madison comenta que os pais fundaram uma entidade beneficente que emprega relações públicas para emitir press releases que divulgam a generosidade deles. É óbvio que o desperdício de produtos, tais como os cartões comprados pela mãe de Madison, liga-se à sustentação de serviços sem qualquer relevância, envolvidos na produção, na venda ou na publicidade. A descartabilidade dos produtos impulsiona o obsessivo consumismo egera, igualmente, empregos descartáveis e sem importância para o crescimento pessoal ou para uma possível contribuição social. Nessa dimensão, segundo Bauman (2001, pp.146 e 187), a cena do consumo, com a concepção de que a manipulação da transitoriedade é um privilégio e de que a ponderação sobre a durabilidade é um sintoma de privação, acaba por dar ao emprego o mesmo valor do efêmero, de uma flexibilidade que interpreta compromissos como obstáculos de oportunidades futuras. Acontece que, embora a alta rotatividade nos empregos encontre elogios quando se analisa o fenômeno do surgimento da geração Y, na realidade, a supervalorização da transitoriedade e da flexibilidade em postos de trabalho permite o aumento de serviços com contratos de curto prazo ou sem quaisquer contratos, combinado à elevação da ausência de cobertura previdenciária (BAUMAN, 2001, p.169).

No capítulo seguinte, o romance de Chuck Palahniuk ironiza uma das profissões que mais prolifera nos mercados globais de serviços e que menos aparece: o operador de telemarketing. Os operadores de telemarketing lubrificam toda uma série de serviços pertinentes à venda dos produtos mas, de nenhuma maneira, a contínua aceleração do consumo reverbera em recompensas no âmbito profissional. Esse emprego é um dos mais desgastantes fisicamente (por movimentos repetitivos) ou psicologicamente (por lidar com diversas pessoas 
indispostas ao serviço ofertado). Não é à toa que Palahniuk compara os operadores de telemarketing a pessoas mortas que habitam o inferno: embora fortaleçam o sistema de vendas do capitalismo pós-industrial, são rejeitados como modelo de emprego, são hostilizados muitas vezes pelos setores gerenciais da empresa ou pelos consumidores e, em meio ao automatismo da função, perdem a criatividade e a espontaneidade (não pertinentes ao exercício do trabalho). Outra comparação realizada é a dos operadores de telemarketing com os modelos pornô da internet: para a protagonista do romance, a expressão da morte reside em ambos (PALAHNIUK, 2013, p. 126). Se, por um lado, o desgaste constante e a falta de liberdade criativa na profissão de operador de telemarketing robotizam o comportamento humano com seus protocolos repetitivos de fala e de atendimento; por outro lado, a excitação advinda das fotos pornográficas da Internet exprime intensamente o caráter remoto dos atos sexuais ali encenados - aqueles que veem as fotos fingem realidade estando distantes da ação, e os modelos que são envolvidos na montagem do ato sexual distanciam-se da realidade fingindo o sexo. ${ }^{2}$ Como metonímia de uma parte considerável dos empregos contemporâneos, os operadores de telemarketing se definem pela morte: o esvaziamento da criação ou da própria ação modula comportamentos e paralisa a possibilidade de uma atividade que instigue soluções inusitadas e significativas.

\section{CONCLUSÃO: OS REFÉNS DAS DÍVIDAS E A HIPOCRISIA SOBRE UM PROBLEMA PLANETÁRIO}

Apesar de Condenada perseguir a polissemia da palavra inferno, observando-se os valores disseminados pela sociedade estadunidense, no final do romance, a partir do termo inferno, Palaniuhk busca organizar um signo que possa ser generalizado e, em seguida, atacado mais frontalmente. O preenchimento desse signo ocorre de forma a apontar a ausência de liberdade nesse tipo de ordenação social, em meio à ilusão do mérito e da satisfação pessoal. A política de endividamento econômico

\footnotetext{
2 No início da década dos anos 20, Thomas Ruff, para compor a série Nus, baixou fotos pornográficas da internet e acentuou a granulação delas, fornecendo a impressão desse aspecto distanciado do sexo em fotos que retratavam ou sugeriam o ato. Cf. COTTON, 2013, p. 213.
} 
a que se submete tanto o Estado quanto o cidadão estadunidense, além de gerenciar o autoaprisionamento de grande parte dos indivíduos em tarefas de Sísifo, retira uma percepção mais coletiva sobre a resolução de problemas de larga escala social.

Acontece que a dívida advinda do estímulo ao consumo de determinados produtos (aqueles que reforçam a concepção de liberdade individual ou de integração social por meio da posse deles), concomitante com a preocupação das pessoas com seu o poder salarial, leva à obsessão pela luta constante contra uma possível instabilidade danosa à manutenção doméstica. Por ser uma possibilidade sempre presente, essa situação não permite que outros juízos mais gerais, longe da esfera do orçamento familiar (sobre a política econômica, por exemplo), possam ser gestados. Ademais, na contemporaneidade, a associação entre a descartabilidade dos produtos e o elogio à facilidade das trocas de contratos na esfera do trabalho torna, em muitos casos, tanto os empregados (que descartam deveres e empregos no intuito da abertura por novas oportunidades) quanto os empregadores (que substituem empregados por outros como se fossem peças mais baratas) pessoas com um senso frágil de compromisso coletivo e com ideias de conquista meramente ligadas à possibilidade do lucro individual ou corporativo.

A crítica à descartabilidade das pessoas, de seus objetos de posse ou de seus objetivos numa sociedade de consumo - já plenamente discutida em Clube da luta - retorna ao romance Condenada, de Chuck Palahniuk, de modo distinto, ao evidenciar a maneira pela qual o inferno do endividamento e das escalas de consumo sugere uma ida enganosa ao Paraíso. O segundo volume dessa trilogia, chamado Maldita, lançado em 2013, discute, também de forma alegórica e sarcástica, as consequências do consumismo desenfreado e do estímulo ao endividamento: o colapso da economia mundial em 2009.

\section{REFERÊNCIAS BIBLIOGRÁFICAS}

BAUMAN, Zygmunt. Modernidade líquida. Rio de Janeiro: Zahar, 2001.

BEY, Hakim. Milênio; Por e contra a interpretação; Religião e revolução; Notas sobre o nacionalismo. Porto Alegre: Deriva, 2012.

COTTON, Charlotte. A fotografia como arte contemporânea. São Paulo: Editora WMF e Martins Fontes, 2013. 
FORTINO, Carla (Ed.). O livro da economia. São Paulo: Globo, 2013.

FOUCAULT, Michel. Microfísica do poder. Rio de Janeiro: Edições Graal, 2006.

JACOBY, Russell. O fim da utopia: política e cultura na era da apatia. Rio de Janeiro: Record, 2001.

MARTÍN-BARBERO, Jesús. Dos meios às mediações: comunicação, cultura e hegemonia. Rio de Janeiro: Editora UFRJ, 2006.

O JEITO Google de trabalhar. Direção: Ted Remerowisk. Produção: National Geographic. Comentarista: Ted Remerowisk. Estados Unidos, 2010. 1 DVD (45 min), widescreen, color.

PALAHNIUK, Chuck. Clube da luta. São Paulo: LeYa, 2012.

PALAHNIUK, Chuck. Condenada: a vida é curta, a morte é eterna. São Paulo: LeYa, 2013.

PALAHNIUK, Chuck. Maldita. São Paulo: LeYa, 2014.

THE MONEY masters. Direção:William T. Still. Produção: Patrick Carmack. Comentarista: William T. Still. Estados Unidos, 1996. 1 DVD (210 min), widescreen, color.

ZEITGEIST, the movie. Direção: Peter Joseph. Produção e Distribuição: Estúdio GMP. Comentarista: Peter Joseph. Estados Unidos, 2007. 1 DVD (119 min), widescreen, color.

ZEITGEIST: addendum. Direção: Peter Joseph. Produção: Zeitgeist Films. Distribuição: zeitgeistmovie.com. Comentaristas: Peter Joseph, Jacque Fresco, Roxane Meadows, John Perkins e outros. Estados Unidos, 2008. 1 DVD (123 min), widescreen, color.

ZEITGEIST: moving forward. Direção e Produção: Peter Joseph. Distribuição: GMP LLC. Comentaristas: Peter Joseph, Jacque Fresco, Roxane Meadows, Ashton Cline, Robert Sapolsky, Adrian Bowyer, Colin J. Campbell, James Gilligan, Gabor Maté e outros. Estados Unidos, 2011. 1 DVD (162 min), widescreen, color. 